\title{
Welcome to the world of glass!
}

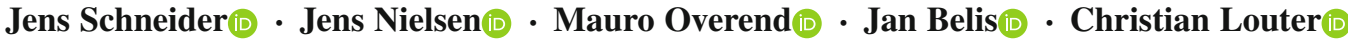

Published online: 10 July 2019

(C) Springer Nature Switzerland AG 2019

The world of glass in an engineering context requires by nature to have a detailed view down to the microand sometimes the nanoscale on the materials involved and still keep a broad view on the macroscale for the structures we build and the loads to which they are exposed.

This new issue of Glass Structures and Engineering relates to this: You will find papers on glass performance for better blast protection on a façade scale (Lori et al. 2018) as well as experimental glass strength investigations under high loading rates that require an understanding of the glass microscale (Meyland et al. 2018). While the paper by Husser et al. (2018) shows the potential of subdivided switchable sun protection glazing, the brief report by Pascual et al. (2019) on the flexural response of large scale steel-framed composite glazing panels requires the understanding of the complex structural interaction of the different materials involved. For the engineering design of laminated glass, the review paper by Kuntsche et al. (2019) gives an

J. Schneider $(\varangle) \cdot J$. Nielsen · M. Overend

Technische Universität Darmstadt, Darmstadt, Germany

e-mail: schneider@ismd.tu-darmstadt.de

J. Belis

Department of Structural Engineering, Ghent University,

Ghent, Belgium

e-mail: jan.belis@ugent.be

\section{Louter}

Institute of Building Construction, Technische Universität

Dresden, Dresden, Germany

e-mail: christian.louter@tu-dresden.de

URL: http://bauko.bau.tu-dresden.de overview on the current methods, standards and technical approvals and their practical implications for typical engineering design tasks. Finally, the papers by Brokmann et al. (2018) on the failure strength of automotive windscreen glass, by Nielsen et al. (2019) on the strength effects of drilling in tempered glass and by Pourmoghaddam et al. (2018) on the fracture pattern of thermally tempered glass again dig into the microscale and relate the results of the research to the macroscale.

It is clear, that almost none of our engineering design, realization and performance challenges with glass can be solved if we do not use a real multi-scale and multi-disciplinary approach both from a theoretical and from an experimental point of view. This makes glass engineering special, challenging and constantly opens new horizons-a continuous educational and life-long learning process. Fortunately, we found several new members from all over the world who share our vision of glass engineering; in total, our Editorial Board now consist of 24 internationally renowned experts in the field of glass structures and engineering.

We warmly welcome them to our Editorial Board!

\section{References}

Brokmann, C., Alter, C., Kolling, S.: Glass Struct. Eng. (2018). https://doi.org/10.1007/s40940-018-0090-9

Husser, M., Haase, W., Sobek, W.: Glass Struct. Eng. (2018). https://doi.org/10.1007/s40940-018-0087-4

Kuntsche, J., Schuster, M., Schneider, J.: Glass Struct. Eng. (2019). https://doi.org/10.1007/s40940-019-00097-3 
Lori, G., Morison, C., Larcher, M., et al.: Glass Struct. Eng. (2018). https://doi.org/10.1007/s40940-018-0088-3

Meyland, M.J., Bønding, C.K.T., Eriksen, R.N.W., et al.: Glass Struct. Eng. (2018). https://doi.org/10.1007/ s40940-018-0089-2

Nielsen, J.H., Meyland, M.J., Thorup, B.E., et al.: Glass Struct. Eng. (2019). https://doi.org/10.1007/s40940-019-00095-5
Pascual, C., Nhamoinesu, S., Overend, M.: Glass Struct. Eng. (2019). https://doi.org/10.1007/s40940-019-00096-4

Pourmoghaddam, N., Kraus, M.A., Schneider, J., et al.: Glass Struct. Eng. (2018). https://doi.org/10.1007/ s40940-018-00091-1

Publisher's Note Springer Nature remains neutral with regard to jurisdictional claims in published maps and institutional affiliations. 